\title{
Analysis of Simvastatin using a Simple and Fast High Performance Liquid Chromatography-Ultra Violet Method: Development, Validation and Application in Solubility Studies
}

\author{
Abubakar Munir, Mahmood Ahmad*, Muhammad Zubair Malik and Muhammad \\ Usman Minhas \\ Department of Pharmacy, Faculty of Pharmacy and Alternative Medicine, The Islamia University of Bahawalpur-63100, Punjab,
} Pakistan.

*For correspondence: Email: ma786_786@yahoo.com Tel: +92-62-9255565

Received: 27 October 2013

Revised accepted: 18 December 2013

\begin{abstract}
Purpose: To develop and validate an accurate, rapid and reproducible reversed-phase high performance liquid chromatography (RP-HPLC) analytical method for the lipid lowering drug, simvastatin, and to apply the developed method to study the solubility of the drug in various oils and surfactants.

Methods: Isocratic RP-HPLC system with a UV-vis detector, and a column with dimensions $4.6 \mathrm{~mm} \mathrm{x}$ $150 \mathrm{~mm}$ and $5 \mu$ particle size, was employed. The mobile phase consisted of methanol and $0.01 \mathrm{M}$ $\mathrm{KH}_{2} \mathrm{PO}_{4}$ phosphate buffer (80:20) at pH 5.5 adjusted with phosphoric acid (2M) and pumped at a flow rate of $1 \mathrm{ml} / \mathrm{min}$. Validation parameters, viz, limit of detection (LOD), limit of quantification (LOQ) linearity, accuracy, precision, and sensitivity, were established. Solubility study was performed in various oils and surfactants at $25^{\circ} \mathrm{C}$ and the developed HPLC method was applied to analyze all samples.

Results: The developed HPLC method showed good linearity $\left(R^{2}=0.9958 \pm 0.0040\right.$. The intra- and inter-day \% accuracy was more than $98 \%$. LOQ and LOQ were 0.160 and $0.484 \mu \mathrm{g} / \mathrm{ml}$ respectively. Simvastatin showed the highest solubility in sesame oil $(15 \mathrm{mg} / \mathrm{ml})$ and in Tween $80(11 \mathrm{mg} / \mathrm{ml})$ at 25 ${ }^{\circ} \mathrm{C}$.

Conclusion: An accurate, rapid and robust HPLC-UV method has been developed, validated and applied successfully to determine the solubility of simvastatin in oils.
\end{abstract}

Keywords: Simvastatin, Validation, Solubility, Sesame oil, Tween 80.

Tropical Journal of Pharmaceutical Research is indexed by Science Citation Index (SciSearch), Scopus, International Pharmaceutical Abstract, Chemical Abstracts, Embase, Index Copernicus, EBSCO, African Index Medicus, JournalSeek, Journal Citation Reports/Science Edition, Directory of Open Access Journals (DOAJ), African Journal Online, Bioline International, Open-J-Gate and Pharmacy Abstracts

\section{INTRODUCTION}

Simvastatin is a $(1 S, 3 R, 7 S, 8 S, 8 \mathrm{a} R)-8-\{2-$ $[(2 R, 4 R)-4$-hydroxy-6-oxotetrahydro-2H-pyran-2yl]ethyl\}-3,7-dimethyl-1,2,3,7,8,8a-

hexahydronaphthalen-1-yl 2,2-dimethylbutanoate that belongs to the statin drug family; the members of which are used as cholesterollowering agents for patients with hypercholesterolemia. This semi synthetic drug exhibits a very important hepatic first-pass metabolism by inhibiting 3-hydroxy- 3methylglutaryl coenzyme-A reductase (HMGCoA) and reduces low-density lipoproteins [1,2]. Structure of simvastatin has been shown in Figure 1. 
<smiles>CCC(C)(C)C(=O)O[C@H]1C[C@@H](C)C=C2C=C[C@H](C)[C@H](CC[C@@H]3C[C@@H](O)CC(=O)O3)[C@H]21</smiles>

Figure 1: Structure of simvastatin

Various methods such as HPTLC [3], electrokinetic chromatography and voltametry [4] have been reported. Based on different techniques several methods like high performance liquid chromatography/mass spectrometry (LC/MS) [5-9], Gas chromatography/mass spectrometry (GC/MS) [10], high performance liquid chromatography (HPLC) [11-14] and high performance thin layer chromatography (HPTLC) [15] have been developed but these methods utilize expensive reagents or buffers as the mobile phase or complex procedures adopted in sample preparation.

Therefore, the aim of this study was to develop a simple and rapid HPLC-UV method to investigate the solubility of simvastatin in various oils and surfactants. The study focus was to explore the solubility profile of simvastatin in various oils and surfactants.

\section{EXPERIMENTAL}

\section{Chemicals and reagents}

Simvastatin was received as a gift from Sami Pharmaceutical (Pvt) Ltd Karachi, Pakistan. All other chemicals used were purchased from Merck, Germany.

\section{Instrumentation}

HPLC system of Sykam S 3210 consisted of isocratic pump (Sykam GmbH HPLC system, Germany) with UV-Detector (Sykam UV/VIS Germany), column (with dimensions of $4.6 \mathrm{~mm} \mathrm{x}$ $150 \mathrm{~mm}, 5 \mu$ particle size) and computer software (Clarity operating software) with Microsoft Windows XP Professional, ultrasonic bath (Fisher Scientific FS $28 \mathrm{H}$ (Germany), centrifuge machine (model 4000 (China), column thermostat (Sykam 4011, Thermo controller, Germany), injection syringe (20 $\mu \mathrm{l}$, Rheodyne Injector, Germany), magnetic stirrer (Gallenkamp, England), membrane filter (Sartorius, $0.45 \mu \mathrm{m}$ pore size, Germany).

\section{Preparation of standard solutions}

The stock standard solution of simvastatin was prepared by dissolving the accurately weighed simvastatin in Methanol. The stock standard solutions were then diluted with methanol to achieve standard working solutions at concentrations of $0.612,1.25,2.5,5,10,20,40$, $80,160,320$ and $640 \mu \mathrm{g} / \mathrm{ml}$ of simvastatin.

\section{Calibration curve}

To construct a calibration curve, standard stock solution of simvastatin was diluted to give concentrations of $2.5,5,10,20,40,80,160,320$ and $640 \mu \mathrm{g} / \mathrm{ml}$. Separate labeled glass centrifuge tubes were used for all the dilutions. Chromatograms for these concentrations were obtained by injecting $20 \mu \mathrm{l}$ of standard solutions. Regression analysis was carried out. A typical chromatogram of simvastatin standard is given in Figure 2 .

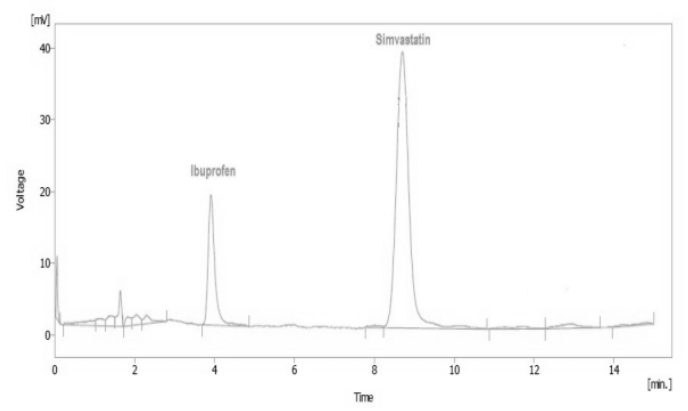

Figure 2: Representative chromatogram of ibuprofen (internal standard) and simvastatin

\section{High performance liquid chromatography}

An isocratic pump with flow rate of $1 \mathrm{ml} / \mathrm{min}$ and UV-detector set at a wavelength of $238 \mathrm{~nm}$, column (with dimensions of $4.6 \mathrm{~mm} \times 250 \mathrm{~mm} 5 \mu$ particle size) and Clarity software for data analysis were employed. The mobile phase consisted of methanol and $0.01 \mathrm{M} \quad \mathrm{KH}_{2} \mathrm{PO}_{4}$ phosphate buffer $(80: 20)$ and $\mathrm{pH}$ was maintained at 5.5 with $2 \mathrm{M}$ phosphoric acid

\section{Linearity determination}

Linearity of the assay method was determined by constructing calibration curve to find out the relationship between instrument response and known concentrations of the analytes. The number of standards used in constructing a calibration curve was selected to the anticipated range of analytical values of simvastatin in the samples of interest. Each drug concentration in three replicates was run in the HPLC system (Sykam S 3210 series) and the data plotted to determine the parameters of standard curve. 


\section{Determination of precision and accuracy}

The accuracy of an analytical method describes the closeness of mean test results obtained by true value (concentration) of the analyte. Accuracy was determined by triplicate based on analysis of low, medium and high concentrations of samples containing known amounts of the analyte. Accuracy in present method was measured by using a minimum of three concentrations in the range of expected concentrations (intra-day). The deviation of mean from the true value served as the measure of accuracy. The precision of an analytical method describes the closeness of individual measures of an analyte when the procedure is applied repeatedly to multiple aliquots of a single homogenous volume of biological fluid (interday). Precision was measured in triplicate at three concentrations in the range of expected concentrations.

\section{Assessment of quantification limits}

LOD and LOQ values were calculated by injecting the solutions with known decreased concentrations of simvastatin into the HPLC system. The limit of detection (LOD) and quantification (LOQ) were then measured by calculating the minimum level at which the simvastatin can be readily detected (signal to noise ratio of $3: 1$ ) and quantified (signal to noise ratio of $10: 1$ ).

\section{Application of method}

The developed HPLC-UV method was applied to determine the solubility of simvastatin in various oils (canola oil, sesame oil, sunflower oil, oleic acid, olive oil, arachis oil and soybean oil), surfactants (Tweens 20 and 80, and Span 85), and co-surfactants (propylene glycol and polyethylene glycol 400). An excess amount of simvastatin was added to separate capped glass vials containing $2 \mathrm{ml}$ of each of the vehicles. After sealing, the mixture was heated at $40^{\circ} \mathrm{C}$ in a water-bath to facilitate solubilization using a vortex mixer. The mixtures were shaken in a shaker apparatus at $25{ }^{\circ} \mathrm{C}$ for $48 \mathrm{~h}$. After reaching equilibrium, each vial was centrifuged at $4000 \mathrm{rpm}$ for $10 \mathrm{~min}$, filtered using a membrane filter $(0.45 \mu, 13 \mathrm{~mm}$, Whatman, USA) and the filtrate suitably diluted prior to injecting into the chromatograph. The concentration of simvastatin was quantified by HPLC as described above.

\section{RESULTS}

Calibration curve parameters of simvastatin have been shown in Figure 2. Mean correlation coefficient $\left(R^{2}\right)$ slope and intercept values were obtained as 0.9958, 228.5 and 45.145 respectively. The developed method showed good linearity with mean correlation coefficient of $0.9958 \pm 0.004$. Limits of quantitation (LOQ) and of detection (LOD) of simvastatin were 0.160 and $0.484 \mu \mathrm{g} / \mathrm{ml}$, respectively. Percent coefficient of variation (CV\%) for both intra- and inter-day was $<2 \%$ which is well within the range of $15 \%$ for lowest and $20 \%$ for highest concentration based on FDA criteria for biological fluids [16]. Intra-day and Inter-day accuracy and precision are shown in Table 1.

Table 1: Intra-day and Inter-day accuracy and precision

\begin{tabular}{llll}
\hline \multirow{2}{*}{ Curve code } & LQC & MQC & HQC \\
\cline { 2 - 4 } & $5 \mu \mathrm{g} / \mathrm{mL}$ & $25 \mu \mathrm{g} / \mathrm{mL}$ & $50 \mu \mathrm{g} / \mathrm{mL}$ \\
\hline Intra-day & & & \\
Batch-01 & 4.97 & 24.8 & 49.88 \\
& 4.98 & 24.75 & 49.52 \\
& 4.89 & 24.62 & 49.48 \\
Batch-02 & 4.87 & 24.72 & 49.67 \\
& 4.93 & 24.82 & 49.76 \\
& 4.87 & 24.76 & 49.69 \\
Batch-03 & 4.98 & 24.98 & 49.98 \\
& 5.00 & 24.75 & 49.96 \\
Mean & 4.97 & 24.80 & 49.97 \\
S.D. & 4.94 & 24.78 & 49.77 \\
\% CV & 0.05 & 0.10 & 0.19 \\
\% accuracy & 1.04 & 0.39 & 0.39 \\
Inter-day & 98.80 & 99.11 & 99.54 \\
Batch 01 & & & \\
Batch 02 & 4.97 & 24.97 & 49.96 \\
Batch 03 & 4.98 & 24.88 & 49.78 \\
Batch 04 & 4.96 & 24.78 & 49.98 \\
Batch 05 & 4.01 & 24.75 & 49.95 \\
Batch 06 & 4.98 & 24.98 & 49.84 \\
Mean & 4.96 & 24.77 & 49.97 \\
S.D. & 0.04 & 24.86 & 49.91 \\
\% CV & 0.89 & 0.10 & 0.08 \\
\% accuracy & 99.27 & 99.42 & 0.17 \\
\hline & & & \\
\hline
\end{tabular}

The proposed method was applied to assess the solubility profile of simvastatin in various oils and surfactants. Simvastatin showed the highest solubility in sesame oil and $(15 \mathrm{mg} / \mathrm{ml})$ and was more soluble in this oil than in Tween 80 (11 $\mathrm{mg} / \mathrm{ml})$. The solubility profile of simvastatin in various media, mainly oils and surfactants, is shown in Table 2.

In the development process, different compositions of mobile phase with several combinations of buffer and organic phases, including acetonitrile, methanol and buffer in 
varying ratios, were tested. The mobile phase, consisting of $\mathrm{KH}_{2} \mathrm{PO}_{4}$ and methanol in the ratio of 20:80 (\%v/v) and with a $\mathrm{pH}$ of 5.5 was chosen. This mobile phase was found to be suitable to achieve the desired objectives of not absorbing at low wavelength and sufficient in concentration to avoid peak tailing since silica-based particles are unstable at low $\mathrm{pH}(<2)$.

Table 2: Solubility of simvastatin in various media

\begin{tabular}{ll}
\hline Medium & $\begin{array}{l}\text { Solubility } \\
(\mathrm{mg} / \mathrm{mL})\end{array}$ \\
\hline Propylene glycol & 4.930 \\
Canola oil & 2.257 \\
Sesame oil & 14.986 \\
Sunflower oil & 1.228 \\
Uleıc acı & 1.033 \\
Tween 20 & 9.172 \\
Olive oil & 4.556 \\
Span 85 & 6.486 \\
Arachis oil & 2.035 \\
Soya been oil & 1.745 \\
Tween 80 & 11.139 \\
Polyethylene glycol 400 & 7.361 \\
\hline
\end{tabular}

\section{DISCUSSION}

Flow rate of $1.0 \mathrm{ml} / \mathrm{min}$. was found appropriate for peak resolution with a short retention time. Similarly, different stationary phases of suitable dimensions were also tried to achieve retention and separation. The run time was short requiring only $15 \mathrm{~min}$ While the retention time for simvastatin was $8.5 \mathrm{~min}$.

The higher solubility of simvastatin in sesame oil and than in Tween 80 is noteworthy. The results suggest that both of these media can be utilized to prepare lipid-based delivery systems to enhance the solubility of simvastatin and thus ultimately increase the bioavailability of the drug,

\section{CONCLUSION}

The findings of this study are significant two major ways, First, an accurate, reproducible and rapid analytical method utilizing commonly available chemicals and technique was successfully developed and validated. Second, the solubility data generated for simvastatin in various various media could be helpful in formulating lipid-based formulation of the drug to enhance its solubility of this poorly soluble agent. It is seems feasible therefore that microemulsions of simvastatin can be developed to improve bioavailability based on the solubility data generated in this study.

\section{ACKNOWLEDGEMENT}

Authors acknowledge the Islamia University of Bahawalpur-Pakistan for providing financial support to complete this project.

\section{REFERENCES}

1. Lennernas $H$, Fager $G$. Pharmacodynamics and pharmacokinetics of the HMG-CoA reductase inhibitors. Similarities and differences. Clin Pharmacokinet 1997; 32: 403-425.

2. Bays HE, Moore PB, Drehobl MA, Rosenblatt S, Toth $P D$, Dujovne CA, Knopp RH, Lipka LJ, LeBeaut $A P$, Yang $B$, Mellars LE, Cuffie-Jackson C, Veltri $E P$. Effectiveness and tolerability of ezetimibe in patients with primary hypercholesterolemia: pooled analysis of two phase II studies. Clin Ther 2001; 23: $1209-1230$

3. Vickers S, Duncan CA, Chen IW, Rosemary A, Duggan $D E$. Metabolic disposition studies on simvastatin, a cholesterol-lowering prodrug. Drug Metab. Dispos. 1990; 18: 138-145.

4. United States Pharmacopoeia, USP30-NF25, Pharmacopeial Forum. 2002, 32(1), p 3179.

5. Barrett B, Huclova, Borek-dohalsky V, Nemec B, Jelinek I. Validated HPLC-MS/MS method for simultaneous determination of simvastatin and simavastatin hydroxyl acid in human plasma. J Pharm Biomed Anal 2006; 41: 517-526.

6. Ramakrishna $N$, Koteshwara $M$, Vishwottam $K$. Chromatography-mass spectrometry methods for the quantitation of statin in biological samples. $J$ Pharm Biomed Anal 2007; 44: 379-387.

7. Basavaih K, Devi OZ. Cerimetric determination of simvastatin in pharmaceuticals. Based on redox and complex formation reactions. Ecl Quim Sao Paulo 2008; 33: 21-28

8. Yang AY, Sun L, Musson DG, Zhao JJ. Application of a novel ultra low elution volume 96-well solid phase extraction method to the LC/MS/MS determination of simvastatin and simvastatin acid in human plasma. J Pharm Biomed Anal 2005; 38: 521-527

9. Bhavin NP, Naveen S, Mallika S, Pranav SS. Simultaneous determination of simvastatin and simvastatin acid in human plasma by LC/MS/MS without polarity switch: application to a bioequivalence study. J Separat Sci 2008; 31: 301313

10. Takano $T$, Abe S, Hata S. A selected ion monitoring method for quantifying simvastatin and its acid form in human plasma, using the ferroceneboronate derivative. Biomed Environ Mass spectrum 1990; 19: $577-581$

11. Fabio P, Gomes, Pedro LG, Joao MP, Anil KS, Erika $R M$. UV-Derivative spectrophotometric and stability-indicating high performance liquid chromatographic methods for determination of simvastatin in tablets. Lat Am J Pharm 2009; 28: 261-69.

12. Lucie N, Dalibor S, Solich P. HPLC methods for the determination of simvastatin and atorvastatin. Trends Anal Chem 2008; 27: 352-367.

13. Carlucci G, Mazzeo $P$, Biordi L, Bolonga $M$. Simultaneous determination of simvastatin and its hydroxyl acid form in human plasma by high performance liquid chromatography with UV detection. J Pharm Biomed Anal 1992; 10: 693697.

14. Ochiai $H$, Uchiyama $N$, Imagaki $K$, Hata S, Kamei $T$. Determination of simvastatin and its active metabolite in human plasma by column-switching high performance liquid chromatography using 
fluorescence detection after derivatization with 1 bromoacetylpyrene. J Chromatogr B Biomed Sci Appl 1997; 694: 211-217

15. Pravish KT, Padmakar S. Development and validation of HPTLC method for niacin and simvastatin in binary combination. Adv Biosci Biotech 2010; 1: 131-135.
16. US Food and Drug Administration, 2001 [cited 2012 Dec 12] Available from: http://www.fda.gov/cder/ guidance/index.htm. 